\title{
Jean-Louis Dessalles, Către originile limbajului. $O$ istorie naturală a vorbirii. Traducere de Alexandru Gafton. Prefață de Alexandru Gafton și Ioan Milică, Editura Universității „Alexandru Ioan Cuza”, Iași, 2017, 589 p.
}

\author{
Adina Chirilă* \\ Faculty of Letters, History and Theology, West University, Bd. Vasile Pârvan 4, 300223 Timişoara, Romania
}

Nowadays, it would be difficult to name an academic discipline which, striving to clarify one fact or another about the ontology of the living, would not demand to have a word about the origin and evolution of language, from biology to philosophy, from computer sciences to archaeology. Even sciences and domains whose intellectual products don't refer to human communication at all are in the position to offer pieces of knowledge that help in the quest for the truth desired by the evolutionary linguisticslinguistics that, until not long ago, used to rely exclusively, and therefore limitingly, on the data obtained by historical linguistics, construction grammar, cognitive semantics, psycholinguistics, and the like. It's not as if the above-mentioned fields and sciences have recently opened to what seems to be the ultimate mystery of the human species; on the contrary, the linguistics itself has quite recently embraced the idea that some keys to decipher it might be deduced or perfectioned by analysing the evidence given by evolutionary biology, and by taking into account ideas about an increased brain capacity, about the evolution of cognitive and perceptual abilities, about an increased social and ecological complexity, etc.; and not necessary, and not only at Homo sapiens.

Undoubtedly, an interdisciplinarity as such is the chance to obtain an answer to the question Why we talk? ${ }^{1}$. Nevertheless, its capitalization is conditional on bringing forth, on each level and stage of research, various elements of knowledge that would function as solid premises for the next stages and would reduce the need to revisit the same issues, again and again.

With Aux origines du langage. Une histoire naturelle de la parole ${ }^{2}$, Jean-Louis Dessalles ${ }^{3}$ aims at doing that, by clarifying the circumstances that led to the emergence of the human language, as a function advantageous to the species (and, firstly, to the individuals within), and, consequently, preserved in the process of natural selection. While successful in constructing an original theory that joins others at least equally interesting and new at their time ("the exchange of information and cooperation", "the consolidation of social relations", "the negotiation", "the need to dominate rival groups", "the narration of real or imaginary events", "the necessity to clarify one's own ideas", "language - consequence of intelligence", or "the reciprocal dependency of brain development and language development", etc.), Dessalles doesn't fulfil the previously mentioned condition.

The main thesis of the book is that language appeared and set apart the human evolutive lineage thanks to the specificity of the (political) niche in which Homo got to live; the origin of the articulate language is to be found in a context dominated by dramatic changes in hominin relations, probably caused by the invention of lethal weapons and the habit of using them on each other ${ }^{4}$.

The theory is exposed in the third part of the

\footnotetext{
*Email address: chiriladina@yahoo.com.

${ }^{1}$ See the English version of Jean-Louis Dessalles' book, Why We Talk: The Evolutionary Origin of Language. Translated by James Grieve, Oxford University Press, 2007.

${ }^{2}$ Paris, Hermès Science Publications, 2000.

${ }^{3} \mathrm{He}$ works in the field of computer and cognitive sciences, and artificial intelligence; is a professor at École Nationale Supérieure des Télécommunications, Paris (Télécom ParisTech).

${ }^{4}$ See also Dessalles (2010a, p. 7-8): "This hypothesis concerning the role of information competence in the protection against surprise killing satisfies all the hypotheses of the FSM [Friendship Signalling Model] model. [...] The need to signal any form of unexpectedness explains in part why lexicon must be large and learned [...]. And most importantly, it explains why individuals feel the urge to be the first to tell about any unexpected event [...]. This first-to-tell behaviour, characteristic of many human conversations, suggests that language may have originated as a way to secure protection. It is reminiscent of alarm calls among primates. Standard
} 
book, The ethology of language (Introduction and chapters $13-17$, p. 268-3595); the other twoThe place of language in human evolutionary history (chapters 1-6, p. 3-138) and The functional anatomy of speech (chapters 7-12, p. 139-267) - are, concurrently, compendia of more or less familiar issues (e.g. the animal communication, the intercultural linguistic variation, the predecessors of human language, the functional model of language), and critical syntheses of anterior solutions to the question Dessalles is trying to answer, evaluated as incomplete, erroneous or groundless (although - at least some of them-"attractive", p. 87), the result of "ignorance of the constraints of evolution" (p. 115) ${ }^{6}$. In his opinion, taking cooperation (e.g.) into serious account (an idea found explicitly or implicitly in many a theory, stemming from the premise of a honest exchange of accurate information, to the benefit of the receiver ${ }^{7}$ would mean to ignore the reality of the human use of language, namely that it is randomly multidirectional, that individuals often engage in futile conversations, don't seem to care about the identity of the listeners, etc.-conditions that don't harmonize with the principle observed so far by researchers, i.e. of a controlled and selective divulging of information, since every piece of it is assimilated to an asset gained with some costs. It follows that "[a]ny evolutionary account of language origins must explain why talking individuals did better than nontalking (or less-talking) individuals of their reproductive population. Moreover, the difficult point is not to explain how language benefits listeners, but how it benefits speakers" (Dessalles, 2010b, p. 852).

The first part of the book corresponds to the first stage in problematization, in which "we can put the language behaviour into the broader context of the evolution of species" (p. 2), although only the last two chapters constitute the beginning of Dessalles' argumentation. First, by means of analogy with other natural features, he argues, against Chomsky's "catastrophic and non-adaptative" theory, that language is not the product of hazard, but is subject to the action of natural selection; there are two reasons for that: "1) Language, insofar as it is universal, shows a quite marked feature of design [...]. It would be difficult to argue that, other things being equal, capacity for language has no bearing on the relative reproduction of individuals" (p. 114115). It's a process of evolution by natural selection that happens on two different temporal scales, that alternate and repeat themselves, and which force a given population through macroevolution (slow, discontinuous, non-directed), and microevolution (rapid-but not instantaneous-, gradual, and directed) (p. 119). The French researcher shows this mechanism by a technique specific to the field of artificial intelligence: genetic algorithms (p. 119 et seqq.); the scenario and the mission (to escape from a labyrinth) force the program to find solutions that can be extrapolated to the realm of the living: " $[t]$ he population is in a constant state of equilibrium; at any given moment, most of the individuals in the genetic algorithm are following more or less the same path inside the maze. There are of course mutants which try other paths; but since their genome offers them no useful instructions on how to find their way through areas into which their ancestors have never ventured, their performances are very poor and they are almost certain to be eliminated by the selection working through the algorithm. The population remains trapped inside the solution it has discovered, though it will later turn out to be not as good a solution as others. This is a state known as a local optimum, that is, a position that cannot be bettered by a slight change. The population can spend whole generations exploring a dead end [...] or in a cyclic trajectory [...], without ever discovering how to get out of them, for the simple reason that the variants that try exploring the rest of the maze

CST [Costly Signalling Theory] provides an explanation for some forms of alarm calls directed at non-kin. The hypertrophy of human language may have been, from the start, a consequence of the total unpredictability of danger in our species. Unexpectedness, defined as abnormal structure, is the only signature of potential killing danger. This may contribute to explaining why information has replaced muscles in hominin social displays, and why humans can provide information about 'everything'”.

${ }^{5}$ In the present English version of our review, we refer to the pages of the English edition of Dessalles' book (see the $1^{\text {st }}$ note).

${ }^{6}$ The common error being - as in the case of the apparition of any other organ, during the course of evolution - that of the inverting of the temporal relation between cause and effect, of the confusion between the phenotypic effects of the variations (i.e., different employments of language) and the causes that led to those variations (see p. 112).

${ }^{7}$ With the corollary that the information is not, in fact, requested (and therefore not perceived as necessary) by the receiver, but appears at the initiative of the speaker (see Dessalles, 1998, p. 146). 
are not as good as their conservative fellows. A day may come, though it is unlikely, when a particularly lucky mutant performs quite well, at least as well as the current standard. This gives it some possibility of leaving descendants or even of founding a new species which will follow the path that it contrived to find. The new species will be in a new state of equilibrium at a different local optimum which will be better than the previous one" (p. 122-123; emphasis added). Hence, natural selection is a process of optimization, and Dessalles has no reason to not apply the theory to the issue of language, thus concluding that language must have been a product of microevolution, void of any urgent (inescapable) necessity (p. 362), a local optimum for its biological function, asked for and useful only by and to the species that came to populate a peculiar micro-universe, a new ecological niche ${ }^{8}$ (p. 135-136; see also Dessalles, 2010b, p. 853). And that must have been the case with protolanguage too, in a previous stage.

In this point, the demonstration needs some clarification, and it makes the object of the second part of the book, where "we can analyse the structure of language so as to link it to a biological function" (p. 2). Dealing with different language compartments, Dessalles argues that each of them is locally optimal, so that a) the phonologic faculty could make possible the emergence of a lexicon sufficient to communication (p. 139-164), b) the syntax proved useful in expressing predicative relations (p. 194-209), and c) two semantic competences were able to appear: the ability to elaborate cognitive representations, and the ability to perform thematic segmentations of those representations (p. 232264). Apparently, Dessalles aims at obviating the two problems that hinder the consensus about the origin of language: (1) how did symbolic units emerge and evolve, and (2) how did syntax emerge and evolvedunder (different) selection pressures (see Bickerton, 2007 , p. 511 et seqq.). What he does, however, is to move the question - about issue (1) —on a lower step in time, keeping it open about protolanguage.

If, until now, the reader could not fully apprehend the persuasive mechanism of Dessalles' new theory, this drawback is resolved by considering the central chapters, seeing that the architecture of the book doesn't coincide with the argumentation progress toward the main thesis ${ }^{9}$ : if, on the contrary, the reader expected exactly that, the fact that the issue of syntax-a piece in the construction-is to be resolved ${ }^{10}$ by finalizing the construction itself would expose them to a real petitio principii: "a biological scenario that explains the faculty of communicating logical reasoning will justify the existence of thematic segmentation; indirectly, the appearance of syntax, which is of such great service to thematic segmentation, will also be justified” (p. 263). Dessalles' approach is to highlight linguistic facts and habitudes whose existence and manifestation cannot be satisfactorily explained but through the scenario exposed in the last part of the book.

Within the third segment of his demonstrationwhere "we can identify the conditions which may have made such a biological function advantageous" (p. 2)-Dessalles begins by accepting the general notion that information has value, in point of what an individual had to spend (time and energy) in order to get it, and of the risks that individual had to be exposed to in the process; and he reasons further on that any context in which the information is to be disclosed to a listener must be understood as revolving around the advantage gained by the speaker. What exactly do the speakers gain by striving to be relevant $^{11}$, and by "wasting" the information they

\footnotetext{
${ }^{8}$ For the extension of the concept of a new ecological niche construction and comprehension of its implications and consequences for the theory of evolution, see Odling-Smee et al. (2003), e.g. p. 2-3: "Niche construction may (1) in part, control the flow of matter through ecosystems (ecosystem engineering), (2) transform selective environments to generate a form of feedback that may have important evolutionary consequences, (3) create an ecological inheritance of modified selection pressures for descendant populations, and, finally (4) provide a second process capable of contributing to the dynamic adaptive match between organisms and environments".

9"The book is designed as a progression: my aim in Part I is to pose the problem; Part II analyses the reasons underlying the functional components of language; and Part III suggests a coherent explanation” (p. 43).

${ }^{10}$ See p. 568: "here is a capacity which was selected as a way of guarding against lying, before itself becoming a component of communication. [...] In this way, syntax arose, as a way to distinguish among the elements of a situation (typically theme, reference point, and agent) while marking a simple relation among them (typically a topological one). By extension, syntax became a way of referring to entities"; cf. Dessalles (2010b, p. 856; see here also the note to Dessalles, 1998): "[i]n this scenario predication, argumentation and, indirectly, syntax evolved as an anti-liar device".

${ }^{11}$ Relevance is seen as a function of two variables concerning the content of what is going to be said: a) the more probable, the less relevant; b) the more important for the receptor, the more relevant (cf. Dessalles, 1998).
} 
painfully obtained, knowing that their interlocuters may selfishly use it and never respond with the same generosity? The answer of the French professorstatute!-is inspired by Zahavi's theory of prestige and proved by digital simulations that show that an "altruistic behaviour, even if it is costly, can be evolutionary stable as long as it provides the performer with opportunities to establish profitable alliances" (Dessalles, 2010b, p. 856).

Language is an instrument for signalling the speaker's ability to be relevant, to possess valuable and accurate pieces of information before all others, to deserve the confidence the others have in them; it generates prestige and statute, and, consequently, secures the chance of finding partners for reproduction. Thus, Homo loquens functioned as Homo politicus first, in a society in which individuals formed coalitions of necessity, in order to survive and procreate (this would be the biological stake of our linguistic behaviour, whose motivation is to be found in our species' phylogeny $)^{12}$.

Eventually, the biological perspective upon language is in the position to inspire (see chapter 18, Epilogue) a better understanding of human interactions; it also may lie at the bedrock of some prediction concerning the social phenomena, since, like their fellows from the dawns of humanity, the individuals from the digital era are dominated and led by a biological programming that has been selected for the preservation of the species. Obviously, this idea grants no role to culture in the genesis of language.

Jean-Louis Dessalles' book reaches an impressive level of interdisciplinarity and its thesis is grounded on theories and computations-probabilities, digital simulations, calculus-that discourage the thought of a possible different point of view on the matter, if that thought is to come from the average reader interested in the problem of language evolution. However, on a different level, the same two qualities put the theory in an uncomfortable position. Researchers from disciplines of narrow specialization (not necessarily preoccupied with the central issue of the book) may evince that the database, information end evidence Dessalles derives benefit from are incomplete, saddled with a (accidental or deliberate-it doesn't matter) harmful selectivity. Then, operating in mathematical terms requires a verification on the same grounds, with the same level of exactitude; but an approach as such, if the researcher decides to take into consideration an additional condition in configuring the evolutive model of the genus Homo and their language (and nothing can stop the probabilist to do it, since the first stages of our species are white spaces), leads to a different result. Here, the criticism doesn't aim at the correctness of the result, but at the span and complexity of the data used as premises.

The theory of the political origin of language is correct and indicates the truth, if the reader accepts the very premises that its author has accepted. However, the reader cannot be allowed such limitation.

Some of the flows in Dessalles' demonstration was discussed in a symposium brought about by the apparition of the English version of the book (see Symposium, p. 858-888); others, in the Preface of the present edition ${ }^{13}$, in Romanian. These observations represent reactions any reader of this book ought to not overlook, if they want to gain from the contact with Jean-Louis Dessalles' Why We Talk / [Rom.] Către originile limbajului. O istorie naturală a vorbirii something more than a new admissible and interesting solution to an important problem.

\footnotetext{
${ }^{12}$ Jean-Louis Dessalles sees his theory proven by how we communicate using the internet nowadays: "What the Web offered was a way for people to draw attention to themselves. [...] In this way, those who put their pages on the Web are following their biological programming, exactly as they do when talking with friends. What both cases have in common is the display of a competence with the aim of being appreciated [...]. This book's analysis of the biological role of language turns a misleading appearance back to front: the Web is not a mere device for getting information; it is first and foremost a new way for people to attract the attention of others by supplying information they may find useful" (p. 366).

${ }^{13}$ The translation provides the Romanian reader with the chance to know comfortably a pertinent voice in the contemporary discussions concerning one of the most obsessing issues of the human history; it is a beyond doubt gain, be it only because " $[\mathrm{t}]$ he greatest merit of the author and of his work is that-after having comprehended the material fundament of reality and the consistent unity of all forms of manifestation within reality-the effort to examine the subject in discussion and its elements answers to this conception, whose verity it tries to demonstrate and spread. The evolutionary and epistemological perspectives tend to subordinate all the elements of discussion, beginning with the main theme of the book, continuing with the thematic and conceptual subdivisions, with the major or minute elements, going through the operating concepts the methods and instruments that he uses, and ending with the way in which Dessalles organizes his scientific discourse. In this context, one of the valuable ideas promoted by Jean-Louis Dessalles is that
} 


\section{Bibliography}

Bickerton, D. (2007). Language evolution: A brief guide for linguists, in "Lingua”, vol. 117, no. 3, p. 510-526, CrossRef.

Dessalles, J.-L. (1998). Altruism, Status, and the Origin of Relevance, in J.R. Hurford, M. Studdert-Kennedy \& C. Knight (eds), Approaches to the Evolution of Language: Social and Cognitive Bases, Cambridge University Press, p. 130-147.

Dessalles, J.-L. (2010a). Providing information can be a stable non-cooperative evolutionary strategy, Paris: Technical Report, Télécom ParisTech, D025, p. 1-15, [online].

Dessalles, J.-L. (2010b). Précis of Why We Talk, in Symposıum, p. 851-857 și 889-899.

Odling-Smee, F.J., Laland, K.N. \& Feldman, M.W. (2003). Niche Construction: The Neglected Process in Evolution, Princeton University Press.

Symposium = Symposium on J.-L. Dessalles's Why We Talk [OUP, 2007]: Précis by J.-L. Dessalles, commentaries by E. Machery, F. Cowie, and J. Alexander, Replies by J.-L. Dessalles, in "Biology \& Philosophy", vol. 25, no. 5, 2010, p. 851-901.

language has a biological fundament, with its immediate implications: the pre-eminence of language over reason, and the liberation of the language genesis from the notion of culture. The idea is crucial and must be accepted by the linguists (as well as by those who work in the field of social sciences, of the theories of mind, by philosophers, etc.) because a correct understanding (profound and extended) of reality cannot exist without the correct understanding of its origin and evolution” (p. 14-15 of the Romanian edition). 